\title{
Economic model of an innovative enterprise in the digital economy ${ }^{a}$
}

\author{
Daniil Demidenko ${ }^{1}$, Julia Dubolazova ${ }^{1}$, and Ekaterina Malevskaya-Malevich ${ }^{1 *}$ \\ 1 Peter the Great Saint Petersburg Polytechnic University,Higher Engineering-Economical School, \\ Institute of Industrial Management, Economics and Trade, 195251 Polytechnicheskaya st. 29, Russian \\ Federation
}

\begin{abstract}
Currently, the innovation vector is a necessary condition for development of high-tech and high-efficiency industries, a competitiveness factor of enterprise products in market conditions in any economic activity forms. In conditions of transfer to the digital economy, the innovation process - as an incentive for technological modernization of production, increasing of its efficiency and development of new competitive products allows generating relatively high value added that in terms of corporate finance is a key factor in increasing the company market value that in turn is a generally accepted criterion of the economic efficiency of the enterprise activity as a whole.

The article specifies the concept of the economic model of the enterprise that performs innovative activities in conditions of the digital economy. A comparative analysis of the economic model of the enterprise that does not implement innovation and the innovative enterprise is carried out. The economic model of the innovative enterprise proposes a gradual transition from the production of simple goods to science-intensive and hightechnology products by increasing in the level of production development, technologies and skills of employees. The process for formation of the economic model of the enterprise is a mechanism that is a set of elements unified by the system of direct and back links between them and intended to create value added. Based on the performed analysis, it was detected that the innovation enterprise has a number of preferences that compensates for the innovative risk and increases the value added. The model of the value added of the enterprise that performs innovative activity is formulated.
\end{abstract}

\section{Introduction}

In the Russian economic science, the interest in the problems of economic growth is actual based on the introduction of innovations in all areas of activity. Based on these conditions, the development of economic management methods in organizations is primarily aimed at saving all the production factors used to achieve the desired result. The achieved savings are subsequently directed to production expansion and to economic growth with a relatively

\footnotetext{
${ }^{\mathrm{a}}$ The study was carried out with the support of the Grant Council of the President of the Russian Federation (draft NSH - 3792.2018.6)

*Corresponding author: malevskaia@spbstu.ru
} 
lower cost per unit of the obtained result.

In conditions of a new "digital" economy, the concept of economic growth was replaced with the concept of economic development associated with the process of introducing innovations in all areas of activity. In this case, provision for the "innovation" of industrial development and identification of drivers for growth of high-tech and competitive products step forward, and the "classical" methods, tools, criteria of economics lose their practical importance, and their actualization is necessary taking into account the requirements of economy digitalization.

Today, the economics has the most topical issue of innovation; the works of economics classicists are devoted to studies in this field, both at the macro and micro levels $[1,2]$. Thus, Joseph Schumpeter, in the fundamental work "The Theory of Economic Development" [3] introduced the distinction between the concepts of economic growth and economic development into the economics. Economic growth is the increase in the production and consumption of the same goods and services over time, and economic development is the updating of products and production methods, in other words, it means the innovation. According to the definition of Schumpeter, the innovation is a concept that includes five elements: (1) Creation of a new product that is not yet known for the consumer, or a new product quality. (2) Creation of new production methods which have not yet been applied in this industry, which is not necessarily based on scientific discovery and can consist in a new form of commercial commodity circulation. (3) Opening of a new market where this industry has not yet been represented, whether or not the market has existed before. (4) Opening of a new source of production factors, whether or not this source has existed before or was created anew. (5) Creation of a new industry organization, for example, achievement or dissolution of a monopoly position. Thus, the wide concept for innovativeness of any element of the production process is presented.

The actuality of economy "digitalization" is confirmed by the topic of the latest publications of Russian economists. Thus, the work of G.B. Dvas [4] proposes the methodical approach to the development of the regional program for digital economy development combining regional approach to the control with aspects and measures of the program "Digital Economy of the Russian Federation", initialization of aspects and measures reflecting the structure and features of the regional economy.

The latest works of S. D. Bodrunov [5] are devoted to the analysis for the deindustrialization of the Russian economy and foundations for formation of a new industrial society in the framework of the 4th Industrial Revolution. The author deems it appropriate direction to reindustrialization as an instrument for the revival of Russian industry in the context of the need to ensure economic security. It is the author's opinion that the most important component of industrial reinstitutionalization is a new industrial policy at the formal and legislative level of the federal and regional management.

R.S. Grinberg in the work [6], summarizing the system changes in Russia, shows that the existing and predicted economy reforming mechanism often "encourages" the consolidation of trends in the primary economy structure. The author states the approaches to solving the problems of the Russian economy reindustrialization among which the special role is assigned to the "Concept of Economic Sociodynamics" that most adequately reflects modern socioeconomic terms.

The known risk management mechanisms shall be actualized, since innovation activity belongs to a high risk category. The main aspects of innovation activities risks management in the context of globalization are considered in the works of modern authors $[7,8,9]$, as well as issues of practical application of risk management mechanisms known in principle with reference to innovation-active enterprises. $[10,11,12]$

The transition to a digital economy enters upon the question of finding adequate criteria for assessment of economic efficiency of enterprises in a changeable business environment. 
Wealth maximization of shareholders, owners of the enterprise has become a paradigm of corporate management in recent years. The digitization of the economy is based on the approach to the enterprise value-based management. The shareholders wealth is measured by the enterprise activities internal rate of return. In this case, the shareholder's income can be manifested both in dividend payments, and in the growth of the company's market value of stock that is in the growth of equity value or enterprise "capitalization". Information about the company capitalization dynamics is used by the owners to assess the current enterprise economic situation and to predict. [13, 14]

Economic Value Added (EVA) is traditionally considered the best available measure of company value $[15,16,17]$. EVA is recognized by many economists as the most important company performance indicator - the company's management is effective provided that the economic value added increases.

\section{Study target setting}

In the market-economy countries there is the saying: "Economists know the prices of all assets in the world, but they do not know the value of any of them". In a sense, the saying is true - the asset value is the price at which an asset purchase and sale transaction is made in the market. In this case, the question of why the asset value may be below its market price, economists usually redirect to philosophers. If the value is a synonym for the market transaction, then the best indicator of the company's value will be the aggregate price at which its own capital and debts are sold in the financial market. However, in many cases, the use of market prices is unacceptable, it is necessary to have a more accurate and reliable assessment of the market value of assets and the company as a whole.

The reasons for this situation are as follows: firstly, equity is in the hands of shareholders or public companies and is exchanged in this environment, so the market prices may not exist. In addition, company securities are negotiated in the market, but irregularly and in insignificant volumes, therefore, it is impossible to obtain adequate assessments of the market value based on the analysis of purchase/sale prices. As previously stated, the companies' securities are negotiated well, but with a view to obtain commercial benefits from purchase/sale. In practice, independent comparisons of value and market price often reveal a significant number of undervalued assets. The analysts forcedly use the activity control to detect the presence (or absence) of market value growth and, therefore, to evaluate correctness of the economic strategy used by the company.

It follows the need to use special methods to determine the market value or companies' capitalization; this explains the existence of this specific aspect of economic and financial analysis in companies - assessment of their value.

To determine the company market capitalization, there are, as you know, several methods that provide for different accuracy of the assessment results. To compensate for potential risks of unreliable assessment, it is usually performed using different methods according to the applicable standards. The acceptable proximity of the obtained results point to their sufficiency and reliability. All methods are grouped into three approaches which are known based on the appraisal practice - extravagant - a set of methods based on the determination of costs required to restore or replace an object taking into account its wear. Comparative is a set of methods based on the comparison of the object with similar objects in relation to which there is information on the relevant transaction prices. Profitable is a set of methods based on the definition of expected revenues from the facility.

In practice, the most common method for assessment of company capitalization value is precisely the "profitable" method, according to which the current value (at the time of assessment) of future/predicted company income is taken as a capitalization assessment. Pretax or net profit, net cash flow, company's sales value, and other "volumetric" indicators 
featuring the performance of activities can be used as an income indicator. Application of this approach based on the use of forecast data poses risks of unreliable forecasts, but this is currently the only way to obtain an assessment that is not based on previously obtained results. The company's capitalization value is assessed by means of a profitable approach under the following conditions: in every period of activity a normally functioning company can receive revenues from selling the beneficial results of its activities in the market, or from selling the company at the price of capitalization (market value).

Let's consider the relationship between the indicator of the company's economic value added and the efficiency of its activities. The model of economic value added (Value, V) with the relevant required additions to the already known provisions on the formation of the indicator of "economic value added" or "economic profit" can be taken for the economic model of the enterprise (or asset).

The economic model of value added is an economic mechanism, i.e. a set of elements unified by the system of direct and back links between them and intended to create value added as a result of unequivocal use in accordance with the functional purpose (direction of production activity).

As you know, the value added received as a result of investments is:

$$
V=I *(r-i),
$$

where $V$ (Value) is the cost, $I$ is investment, $r$ is the return on invested capital, $i$ is the interest rate or the actual price of money in the financial market.

As is known, the latter is a "risk-free" interest rate identical for all assets " $i_{0}$ " plus an individual risk premium for each asset, or $i=i_{0}+\Delta$. The premium increases the price of purchasing investment and financial resources for investment, while reducing the value added. In the absence of risks (in a perfect competitive market), the purchasing price is equal to the risk-free interest rate, and the risk premium will be zero. When determining the capitalization value, equity market assessment, accounting of faulty assessment risks and other risks by income-based method is of great importance. As it was stated, in case of financial and economic analysis, risks exposure in discounting of cash flows is taken into account through the use of a risk premium relative to the risk-free interest rate. Risk exposure in each period can be determined by different methods of statistics, but it can be assumed that the estimated period is further from the assessment time, the larger risk premium will correspond to it.

The presented economic model of value added includes the elements with nature of both random variables that are realized with a certain probability, and nonrandom elements:

$$
V=I *\left(r-\left(i_{0}+\Delta\right)\right)
$$

Here random elements are " $\mathrm{r}$ " and " $\Delta$ ", as they are realized with a risk which probability is $0 \leq p \leq 1$. If the risk is realized, then $p=1$, a value of risk premium " $\Delta$ " is actual, but in this case income from investments will not be obtained, their profitability is zero " $r=0$ ", since this event comes with a probability of "1-p", with realization of risk $p=1$. Taking into account that the mathematical expectation of a nonrandom value is the value itself, the mathematical expectation of a random value of the economic value added is:

$$
V=I \times((1-p) \times r-(i+p \times \Delta))=I \times(r-p \times r-i-p \times \Delta),
$$


The condition for the significance of the mathematical expectation, the values of the economic model of value added, is its non-negativity $(V \geq 0)$, from which the limit value of the risk premium can be obtained (obvious algebraic transformations are not given):

$$
\Delta \leq \frac{r^{*}(1-p)-i}{p},
$$

For example, if $r=0.2 ; \mathrm{p}=0.1 ; i=0.15$, then the risk loading shall not exceed 0.2 .

\section{Research results}

Therefore, let's state the concept of the economic model of the enterprise that performs innovative activities in conditions of the digital economy. Innovations are traditionally associated with the greater risk. Compensation for the risk is expressed in the risk premium value when calculating the discount rate. It is possible to present the following economic model of a risk premium " $\Delta=\Delta\left(V_{n}\right)$ ".

If we imagine that investment and financial resources are purchased to ensure their asset value, then the higher the value of asset/value added, the lower the risk premium.

$$
V_{n}=I_{n} *\left(r_{n}-\left(i_{0}+\Delta\left(V_{n}\right)\right)\right)
$$

The simplest linear model of the risk premium:

$$
\Delta=\frac{V}{V_{0}} \times \Delta_{0}, \quad 0 \leq V \leq V_{0}, \quad 0 \leq \Delta \leq \Delta_{0},
$$

And the corresponding economic model of value added:

$$
V_{n}=I_{n} *\left(r_{n}-\left(i_{0}+\frac{V_{n}}{V_{0}} \Delta_{0}\right)\right),
$$

Having determined the value of $V_{n}$ from this condition, we obtain:

$$
V_{n}=\frac{I\left(r_{n}-i_{0}\right)}{1+I * \frac{\Delta_{0}}{V_{0}}}
$$

Obviously, the presence of a risk premium reduces the economic value added (the formula denominator always has a positive value and over 1).

Summarizing the above, it is possible to schematically depict the economic model of the enterprise conducting innovation activity (Fig. 1). In this case, the specific character of "innovation" is the introduction of specific financing sources such as government support and innovative financing sources which in turn are the elements of the enterprise innovative mechanism.

Now we understand that the innovative financing sources, for example, are ICO, Initial Coin Offering - the issue of shares or tokens intended to pay for the project's services in the future, as a financing source appeared relatively recently, however, as judged by the volumes of external investments (in 2017, blockchain-projects around the world purchased about $\$ 1.5$ billion during the ICO), it should be taken into account when analyzing alternatives to purchase capital to high-risk projects along with venture capital funding. The 
process is also compared with crowd-funding. The ICO allows you to purchase significant crypto-investment in the economy.

A separate issue may be selected as the "innovations commercialization" block that is the creation of demand for innovative products. In the research formulation, as previously stated, the innovations are any element of the production process, or several elements, or the entire production cycle. In this case, it is obvious that a "new" product does not yet have its consumer when entering into the market. Hence, the need to create demand for the product of the enterprise that conducts innovation activities, as an element of the enterprise economic model.

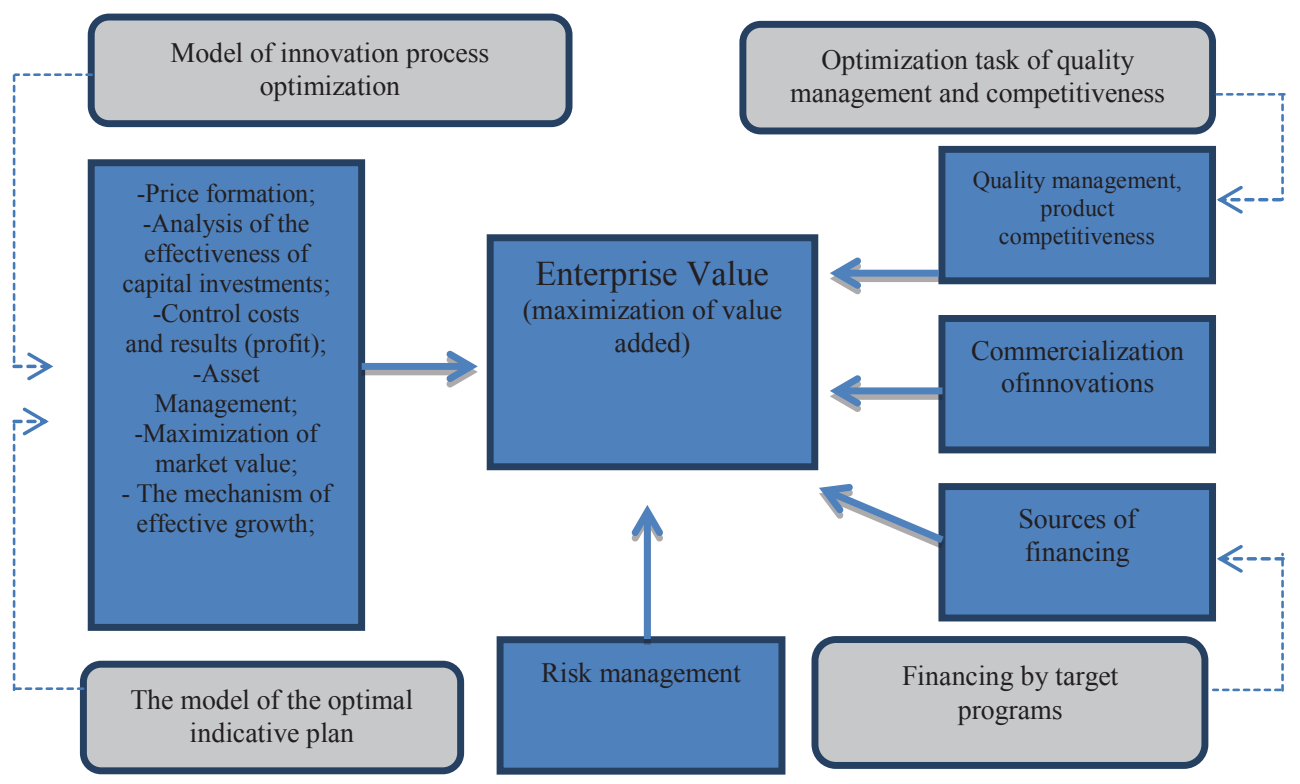

Fig. 1.The economic model of the enterprise that carries out innovative activities.

If the assets belong to the enterprise (which produces innovative products using innovative factors of production - technologies, materials, labor processes), then in the framework of the economic mechanism model it can be assumed that this enterprise has certain preferences (subsidies, concessional lending, etc.). This reduces a risk premium value and prevents the reduction of economic value added in conditions of increased risks associated with innovation. These preferences are absent for "ordinary" non-innovative enterprises and assets that determines the specific nature of the economic mechanism of innovation activity.

\section{Conclusion}

Based on the performed comparative analysis for the model of the economic value added of the enterprise that does not implement innovation, and the innovative enterprise, it can be concluded that the economic model of the innovative enterprise operating in the digital economy is the economic mechanism, i.e. a set of elements unified by the system of direct and back links between them and intended to create value added as the main economic efficiency of the enterprise. In this case, it was detected that the innovation enterprise has a number of preferences that compensates for the innovative risk and increases the value added. The model of the value added of the enterprise that performs innovative activity is formulated. 
As well as, we note that currently the use of processes to assess the market capitalization of companies as the study results significance is a practical aspect of economic analysis and has no serious scientific basis, so the use of optimization principles in the process of assessing the market capitalization value can contribute to improving the scientific level of this aspect.

The study was carried out with the support of Peter the Great St. Petersburg Polytechnic University. We also would like to thank our colleagues, employees of the Engineering and Economical Higher School, Industrial Management, Economy and Trade Institute, who acted as experts that helped to significantly improve the work.

\section{References}

1. R. R. Nelson, National innovation systems: a comparative analysis (Oxford university press, Oxford, 1993)

2. T. E. Burns, G. M. Stalker, The management of innovation (Tavistock publications, London, 1961)

3. J. Schumpeter, The Theory of Economic Development (Direct media Publishing, Moscow, 2008)

4. G.V. Dvas, Formation of regional programs of digital economy development (Saint Petersburg scientific center RAS, Saint Petersburg, 2017)

5. S.D. Bodrunov, Economic recovery of Russia, 1(2017)

6. R. Grinberg,Problems of management theory and practice, 7 (2017)

7. R. Raja, M. B. Sarkar, StrategicManagementJournal, 37.5 (2016)

8. L. V.Nikolova,J.J.Kuporov, D. G. Rodionov, International Journal of Economics and Financial Issues, 5.3S (2015)

9. D. G.Rodionov, L. A. Guzikova, I. A. Rudskaya, Actual economy problems, 8 (2014)

10. D. G.Rodionov, et al., Procedia-Social an dBehavioral Sciences, 207(2015)

11. M. Habermann, M.Swink, A. W. Mackelprang, Journal of Operations Management, 38 (2015)

12. A. Hyytinen, M.Pajarinen, P. Rouvinen, Journal of Business Venturing, 30 (4) (2015)

13. S. D. Young, S. F. O'byrne, D. S. Young, S. Young, Stephen O'Byrne, EVA and valuebased management (McGraw-Hill Professional Publishing, New York, 2000)

14. D. Kyriazis, C. Anastassis, European Financial Management, 13(1) (2007)

15. A. K.Sharma, S.Kumar, International JournalofEconomics and Finance, 2(2) (2010)

16. G.B.Stewart, Journal of Applied Corporate Finance, 7(2) (1994)

17. S.F. O'Byrne, Journal of Applied Corporate Finance, 9(1) (1996) 